\title{
Small dense low-density lipoprotein cholesterol was associated with future cardiovascular events in chronic kidney disease patients
}

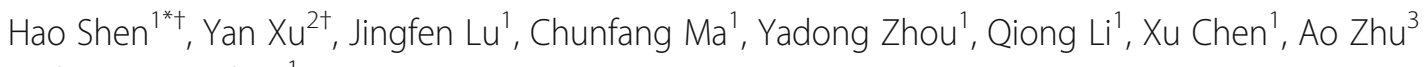
and Guorong Shen ${ }^{1}$

\begin{abstract}
Background: Cardiovascular disease (CVD) is often comorbid with chronic kidney disease (CKD). Small low-density lipoprotein cholesterol (sdLDL-C) has also been found to increase risk for CVD. The goal of the present study was to determine the nature of the relationship between sdLDL-C concentration and CVD in patients with CKD.

Methods: One-hundred and forty-five subjects (113 men and 32 women) with CKD (Stage 3 and Stage 4) participated this retrospective study. The concentration of sdLDL-C was measured in samples from 145 CKD patients between 2010 and 2012 during a four-year follow-up period.

Results: A total of eight fatal cardiovascular events (CVs) and 46 nonfatal CVs were registered in the four-year follow-up period. Multivariate Cox regression analysis showed that sdLDL-C [1.278, $95 \%$ (1.019-1.598)] and sdLDL-C/LDL-C [2.456, $95 \%$ (1.421-15.784)], at final observation, were independent risks of CVs. A Kaplan-Meier survival analysis showed that patients with sdLDL-C $>38 \mathrm{mg} / \mathrm{dl}$ (logrank: 4.375, $P=0.037$ ), and sdLDL-C/LDL-C ratio $>0.3$ levels (logrank: 11 . 94, $P=0.018$ ) were at increased risk for CVs.
\end{abstract}

Conclusion: The results of this study indicated that for patients suffering CKD, a significant relationship exists between an elevated sdLDL-C concentration and the risk of cardiovascular disease.

Keywords: Chronic kidney disease, Cardiovascular diseases, Lipids, sdLDL-C

\section{Background}

Chronic kidney disease (CKD) progression is frequently complicated with dyslipidemia, which is recognized as the most important risk factor causing cardiovascular disease (CVD) in CKD patients. Multiple observational studies have shown that low density lipoprotein cholesterol (LDL-C) is an effective, independent predictor of CVD morbidity and mortality; Small dense LDL (sdLDL) has been associated with increased risk for CVD in a number of cross-sectional studies [1-4]. This is most likely because in large quantities, sdLDL

\footnotetext{
* Correspondence: shenhaojyk@126.com

${ }^{\dagger}$ Equal contributors

'Department of Clinical Laboratory Medicine, First People's Hospital of

Wujiang District, Nantong University, Suzhou, China

Full list of author information is available at the end of the article
}

particles are more atherogenic than larger, buoyant LDL-C particles $[2,5]$.

Though the pathogenesis for the elevated risk of CVD in patients with CKD remains elusive, CVD is indeed the leading cause of death among patients with CKD [6-9]. Studies have shown that sdLDL-C is significantly higher than LDL-C in patients with coronary artery disease and have associated it with the incidence of CVs independently of LDL-C [10, 11]. Accordingly, sdLDL-C seems to be a major and independent CVD risk factor.

To date, there has been no prospective study to assess the association of sdLDL-C with $\mathrm{CV}$ onset in patients with CKD, though doing so is newly possible by virtue of innovative, fully automated, homogenous assay techniques that now allow for the routine inspection of a 
large number of samples. The present study was conducted in effort to determine whether sdLDL-C is an effective (and readily assessed) predictive factor of CVD in CKD patients.

\section{Methods}

\section{Subjects and study design}

A total of 248 non-dialysis CKD patients (Stage 3 to Stage 4) who had no history of treatment with lipidlowering drugs were enrolled in this study from the Renal Unit of Wujiang Affiliated Hospital of Nantong University between December, 2010 and December, 2012. CKD was diagnosed according to the National Kidney Foundation K/DOQI Guidelines [12]. Exclusion criteria included severe hepatic disease $(n=3)$, infectious disease $(n=6)$, current treatment for malignancy $(n=4)$, and known thyroid disorders $(n=2)$, lost during followup $(n=13)$, missing blood examination data $(n=3)$, withdrew consent $(n=1)$, and treatment with lipidlowering drugsduring the follow-up period $(n=71)$. After these patients were excluded, data from 145 participants was ultimately included in the study. The mean age of participants was $65.2 \pm 11.3$ years; the individuals ranged in age from 50 to 72 years. Thirty-four of these participants had a verifiable medical history of CVD at the time of enrollment. Of these 34, 3 had a history of stroke, 26 had a history of previous myocardial infarction, and 5 had a history of peripheral vascular disease. Eighty healthy subjects with similar gender, age and sdLDL-C characteristics as the patient groups served as a control group (mean age $64.3 \pm 10.8$ years, ranging from 52 to 71 years.)

Blood samples were collected and centrifuged immediately after the subjects had fasted for $12 \mathrm{~h}$. The body mass index (BMI), smoking history, and medical history of each participant were collected. A diagnosis of hypertension was given to participants who showed a systolic blood pressure (SBP) $\geq 140 \mathrm{mmHg}$, a diastolic blood pressure (DBP) $\geq 90 \mathrm{mmHg}$ after the first three measurements, or if they had a history of taking anti-hypertensive medications [13]. Diabetes was the diagnosis for a fasting serum glucose registering $\geq 7.0 \mathrm{mmol} / \mathrm{L}(126 \mathrm{mg} / \mathrm{dL})$ or for those with a history of anti-diabetes medications [14]. Dyslipidemia was defined as triglyceride (TG) $\geq 150$ (mg/dl), LDL-C $\geq 140$ (mg/dl), or high-density lipoprotein cholesterol $(\mathrm{HDL}-\mathrm{C})<40(\mathrm{mg} / \mathrm{dl})$ [15]. We calculated the estimated glomerular filtration rate (eGFR) by using the Modification of Diet in Renal Disease (MDRD) equation: $186 \times(\text { serum creatinine })^{-1.154} \times$ age $^{-0.203} \times(0.742$ forfemales) [16]. All relevant data was evaluated between October and December of 2014. The endpoints of the present study were date of the first $\mathrm{CV}$ onset during the follow-up period, death, or the patient's last visit to the Wujiang
Affiliated Hospital of Nantong University. CVs were defined and registered as listed in Table 1 during the follow-up.

\section{Laboratory measurements}

We measured the above parameters for all subjects at the onset of CVs yearly during the follow-up period. Laboratory examination results including serum TG, total cholesterol (TC), HDL-C, LDL-C, fasting blood glucose (FBG), apolipoproteins A1 (ApoA1), B (ApoB), and glycated hemoglobin $(\mathrm{HbA} 1 \mathrm{c})$ were measured via HPLC method [17] and hsCRP was estimated via immunoturbidimetry method using a commercial Beckman Synchron DxC 600 fully automated analyser kit (USA). An sdLDL-EX Seiken kit was used for quantitative determination of sdLDL-C in samples according to the manufacturer's instructions [18].

\section{Statistical analyses}

All statistical analyses were performed in SAS 9.1 software (SAS Institute, Cary, NC, USA). Baseline characteristics were compared between the Event and Non-event groups using a t-test for parametric variables, Wilcoxon tests for non-parametric variables, and Chi-square tests for categorical variables. Differences in cumulative incidence were assessed by log-rank tests in subjects divided into two groups based on the median levels $(38 \mathrm{mg} / \mathrm{dl})$ of sdLDL-C. The Cox proportional hazard regression model was used to identify the most significant factors, adjust them by sex, and determine which differed statistically between event and event-free subjects; $P<0.05$ was considered statistically significant.

Table 1 Cardiovascular events were defined and registered during the follow-up

\begin{tabular}{|c|c|c|c|c|}
\hline \multirow{3}{*}{$\begin{array}{l}\text { Cardiovascular events } \\
\text { defined }\end{array}$} & \multicolumn{4}{|l|}{ Registered } \\
\hline & \multicolumn{2}{|c|}{ Patients $(n=145)$} & \multicolumn{2}{|c|}{ Control $(n=80)$} \\
\hline & Non-fatal & Fatal & Non-fatal & Fatal \\
\hline Heart failure & 1 & 7 & 0 & 1 \\
\hline Ischemic stroke & 2 & 0 & 0 & 0 \\
\hline Hemorrhagic stroke & 4 & 0 & 0 & 0 \\
\hline Acute coronary syndrome & 21 & 1 & 2 & 0 \\
\hline $\begin{array}{l}\text { Coronary or any peripheral } \\
\text { arterial revascularization }\end{array}$ & 18 & 0 & 4 & 0 \\
\hline Total & 54 & & 7 & \\
\hline Events\% & $37.2 \%$ & & $8.8 \%$ & \\
\hline$p^{a}$ & $<0.001$ & & & \\
\hline
\end{tabular}

Data are presented as the number and its percentage (\%). Percentage $=$ the number of each individual category divided by $n$

aindicates the comparison of percentage between Patients group and Control group 


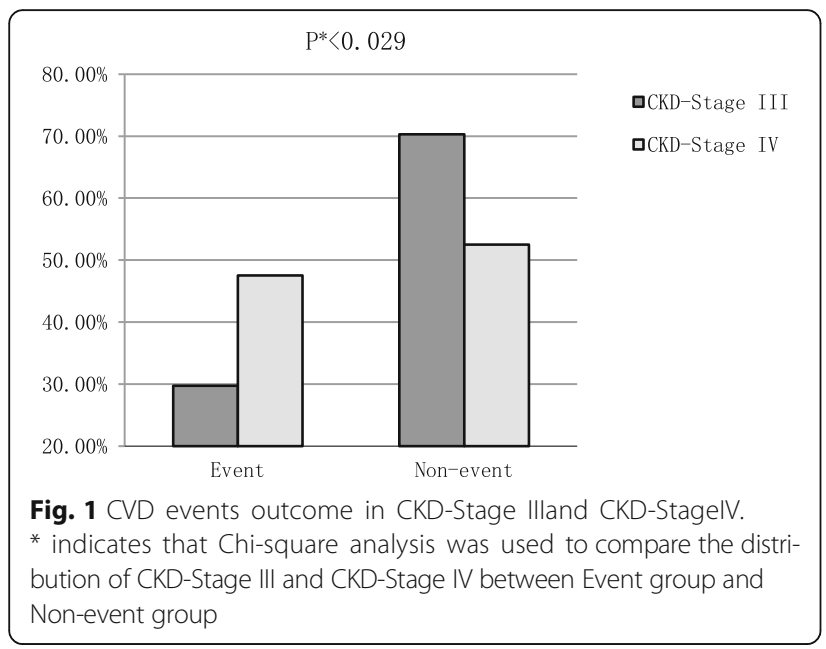

Table 2 The clinical characteristics at baseline of the enrolled patients

\begin{tabular}{|c|c|c|c|c|}
\hline Variable & $\begin{array}{l}\text { All } \\
(n=145)\end{array}$ & $\begin{array}{l}\text { CVs } \\
(n=54)\end{array}$ & $\begin{array}{l}\text { Non- CVs } \\
(n=91)\end{array}$ & $p^{a}$ \\
\hline Men & $113(77.9 \%)$ & $45(83.3 \%)$ & $68(74.7 \%)$ & 0.227 \\
\hline Age(years) & $65.2 \pm 11.3$ & $68.5 \pm 10.5$ & $63.2 \pm 11.5$ & 0.006 \\
\hline Body mass index $\left(\mathrm{kg} / \mathrm{m}^{2}\right)$ & $23.9 \pm 3.2$ & $24.5 \pm 3.3$ & $23.6 \pm 3.2$ & 0.108 \\
\hline \multicolumn{5}{|l|}{ History of cardiovascular disease } \\
\hline Previous myocardial infarction & $26(17.9 \%)$ & 10 (18.5\%) & $16(17.6 \%)$ & 0.887 \\
\hline Stroke & $3(2.1 \%)$ & $1(1.9 \%)$ & $2(2.2 \%)$ & 0.998 \\
\hline Peripheral vascular disease & $5(3.4 \%)$ & $2(3.7 \%)$ & $3(3.3 \%)$ & 0.998 \\
\hline \multicolumn{5}{|l|}{ Cardiovascular disease risk factors } \\
\hline Hypertension & $116(80.0 \%)$ & 48 (88.9 \%) & $68(74.7 \%)$ & 0.039 \\
\hline Diabetes mellitus & $65(44.8 \%)$ & $32(59.3 \%)$ & $33(36.3 \%)$ & 0.007 \\
\hline Dyslipidemia & $123(84.8 \%)$ & $46(85.2 \%)$ & $77(84.6 \%)$ & 0.926 \\
\hline Smoking, current or former & $63(43.4 \%)$ & $23(42.6 \%)$ & $40(44.0 \%)$ & 0.873 \\
\hline Family history & $26(17.9 \%)$ & $12(22.2 \%)$ & $14(15.4 \%)$ & 0.299 \\
\hline \multicolumn{5}{|l|}{ Etiology of CKD } \\
\hline Diabetes & $40(27.6 \%)$ & $14(25.9 \%)$ & $26(28.6 \%)$ & \\
\hline Glomerulonephritis & $22(15.2 \%)$ & $7(13.0 \%)$ & $15(16.5 \%)$ & \\
\hline Hypertension & $36(24.8 \%)$ & $16(29.6 \%)$ & $20(22.0 \%)$ & 0.875 \\
\hline Polycystic kidney disease & $5(3.4 \%)$ & $2(3.7 \%)$ & $3(3.3 \%)$ & \\
\hline Unknown & $42(29.0 \%)$ & $15(27.8 \%)$ & $27(29.7 \%)$ & \\
\hline \multicolumn{5}{|l|}{ Medication } \\
\hline Angiotensin receptor blocker & $65(44.8 \%)$ & $24(44.4 \%)$ & $41(45.1 \%)$ & 0.943 \\
\hline Angiotensin converting enzyme inhibitors & $27(18.6 \%)$ & $14(25.9 \%)$ & $13(14.4 \%)$ & 0.082 \\
\hline Insulin & $7(4.8 \%)$ & $3(5.6 \%)$ & $4(4.4 \%)$ & 0.753 \\
\hline Antiplatelet & 71 (48.9\%) & 25 (46.3\%) & 46 (50.6 \%) & 0.620 \\
\hline
\end{tabular}

Data are presented as mean \pm SD or the number and its percentage (\%). Percentage $=$ the number of each individual category divided by $n$ Abbreviation: $C V s$ cardiovascular events

${ }^{a}$ indicates the comparison of mean or percentage between Event group and Non-event group

\section{Results}

As discussed above, Chi-square analysis was used in this study to compare the distribution of CKD-Stage III and CKD-Stage IV between Event and Non-event groups. As shown in Fig. 1, the distribution was notably different; the percentage of CKD-Stage III in the Non-event group was significantly higher than that of the Event group $(p<0.029)$. Table 1 shows that the prevalence rates of $\mathrm{CV}$ outcomes were significantly higher in the patient groups than the healthy control group $(37.2 \%$ vs. $8.7 \%, P<0.001)$. By comparison of the outcomes of the general and laboratory characteristics between the two groups (Event vs. Non-event) showed that CKD patients with CVs had significantly higher prevalence of diabetes mellitus and hypertension. These differences grew more intense with age, as well. HbA1c, sdLDL-C, LDL-C/HDL$\mathrm{C}$, and sdLDL-C/LDL-C were higher in the Event group than the Non-event group at baseline. ApoA-I, eGFR, and HDL-C levels were significantly lower in the Event group, 
and ApoB, Non-HDL-C, and LDL-C were similar between the two groups (Tables 2 and 3 ).

The unadjusted Cox regression analysis showed that the association was stronger for sdLDL-C/LDL-C than sdLDL-C, age, LDL-C/HDL-C, eGFR, HbA1c, or ApoA-I as they affected the incidence of CVs at the final observation. Increase in LDL-C was not significant in terms of increased risk of CVs, however. After risk adjustment in the multivariate Cox regression analysis, which included the significant predictors above and the marginally significant predictor of $\mathrm{CVs}$ in the univariate model, we confirmed that sdLDL-C/LDL-C had stronger impact than sdLDL-C, age, or HbA1c at final observation. Moreover, LDL-C/ HDL-C was not found to be a statistically significant independent risk factor for CVs (Table 4).

During a median follow-up period of 2.3 years, KaplanMeier survival analysis results showed that sdLDL-C levels were significantly associated with $\mathrm{CV}$ incidence in our participants: Patients with sdLDL-C $>38 \mathrm{mg} / \mathrm{dl}$ levels were at increased risk for CVs (logrank: 4.375, $P=0.037$ ) as shown in Fig. 2, as were patients with sdLDL-C/LDL-C ratio $>0.3$ (logrank: 11.94, $P=0.018$ ) as shown in Fig. 3.

\section{Discussion}

The results of multivariate Cox regression analysis, which included the significant predictors and the marginally significant predictors of $\mathrm{CVs}$ in the univariate model, showed that elevated sdLDL-C concentration and sdLDL-C/LDL-C can be associated with increased CVD risk in CKD patients. We also found that HR was significant after multivariable adjustment and by analysis including gender, age, HbA1c, eGFR, hs-CRP, and other lipid risk factors in Models 1 and 2; sdLDL-C, HbA1c, and sdLDL-C/LDL-C concentrations did remain an independent risk predictor for CVs. In our study, participants with elevated $\mathrm{HbA1c}$ levels were the most at risk for CVs, suggesting that without proper diabetes control, there is an increased risk for CVs. An increase in sdLDL-C/LDL-C also indicated CV risk. An imbalance of cholesterol-poor sdLDL and cholesterol-rich large LDL led to a risk of CVs for patients who did not receive any lipid-lowering medications during the follow-up period. There is evidence that sdLDL formation is related to postprandial hyperglycemia and hyperlipidemia, both of which can lead to CVs. Additionally, the sdLDLC/LDL-C ratio is another risk factor for CVs in CKD patients. Patients with CKD have elevated sdLDL-C/LDL-C, over sdLDL-C, and declining eGFR, are at risk for CVs.

Patients with CKD have significantly increased risk for cardiovascular complications. Traditional risk factors fail to fully explain the high incidence of CVD in CKD patients. Similarly, traditional lipid measures are not sufficient for predicting cardiovascular outcomes in CKD patients $[1,19-21]$. In accordance with the results presented here, previous studies have shown that sdLDL-C is significantly higher than LDL-C in patients with

Table 3 The laboratory characteristics at baseline of the enrolled patients

\begin{tabular}{|c|c|c|c|c|}
\hline Variable & $\begin{array}{l}\text { All } \\
(n=145)\end{array}$ & $\begin{array}{l}\text { CVs } \\
(n=54)\end{array}$ & $\begin{array}{l}\text { Non- CVs } \\
(n=91)\end{array}$ & $P$ \\
\hline $\mathrm{LDL}-\mathrm{C}(\mathrm{mg} / \mathrm{dl})$ & $119.2 \pm 31.2$ & $120.1 \pm 30.2$ & $118.6 \pm 32.4$ & 0.783 \\
\hline $\mathrm{sdLDL}-\mathrm{C}(\mathrm{mg} / \mathrm{dl})$ & $37.9 \pm 21.3$ & $43.4 \pm 26.5$ & $34.7 \pm 20.2$ & 0.027 \\
\hline $\mid \mathrm{bLDL}-\mathrm{C}(\mathrm{mg} / \mathrm{dl})$ & $80.4 \pm 25.5$ & $75.2 \pm 25.4$ & $83.5 \pm 25.2$ & 0.058 \\
\hline sdLDL-C/LDL-C & $0.32 \pm 0.13$ & $0.36 \pm 0.16$ & $0.29 \pm 0.12$ & 0.003 \\
\hline $\mathrm{TG}(\mathrm{mg} / \mathrm{dl})$ & $134.5(91.3-180.5)$ & $132(87.5-176.3)$ & $135.3(93.2-185.6)$ & 0.982 \\
\hline $\mathrm{TC}(\mathrm{mg} / \mathrm{dl})$ & $190.1 \pm 34.9$ & $183.9 \pm 30.4$ & $193.8 \pm 34.8$ & 0.085 \\
\hline $\mathrm{HDL}-\mathrm{C}(\mathrm{mg} / \mathrm{dl})$ & $45.7 \pm 14.2$ & $42.3 \pm 14.8$ & $47.7 \pm 13.2$ & 0.024 \\
\hline Non-HDL-C(mg/dl) & $142.6 \pm 33.6$ & $142.8 \pm 31.8$ & $142.5 \pm 35.4$ & 0.959 \\
\hline $\mathrm{LDL}-\mathrm{C} / \mathrm{HDL}-\mathrm{C}$ & $2.84 \pm 1.12$ & $3.11 \pm 1.16$ & $2.68 \pm 1.06$ & 0.024 \\
\hline Apo A-I (mg/dl) & $119.0 \pm 23.2$ & $111.7 \pm 22.7$ & $123.3 \pm 22.7$ & 0.003 \\
\hline Apo B(mg/dl) & $93.0 \pm 22.3$ & $95.4 \pm 37.3$ & $91.6 \pm 20.7$ & 0.431 \\
\hline $\mathrm{FBG}(\mathrm{mg} / \mathrm{dl})$ & $116.7 \pm 36.2$ & $121.6 \pm 37.3$ & $113.8 \pm 35.8$ & 0.214 \\
\hline $\mathrm{HbA1c}(\%)$ & $6.41 \pm 1.23$ & $6.85 \pm 1.36$ & $6.15 \pm 1.08$ & $<0.001$ \\
\hline hs-CRP (mg/dl) & $0.39(0.16-1.52)$ & $0.53(0.43-1.65)$ & $0.31(0.15-1.48)$ & 0.069 \\
\hline $\mathrm{eGFR}(\mathrm{ml} / \mathrm{min} / 1.73 \mathrm{~m} 2)$ & $50.3 \pm 16.5$ & $45.6 \pm 15.8$ & $53.1 \pm 17.7$ & 0.011 \\
\hline
\end{tabular}

Normal Data are presented as mean \pm SD, and Median (Q1-Q3) are used for abnormal data $\mathrm{lbLDL}-\mathrm{C}(\mathrm{mg} / \mathrm{dl})=\mathrm{LDL}-\mathrm{C}(\mathrm{mg} / \mathrm{dl})-\mathrm{SdLDL}-\mathrm{C}(\mathrm{mg} / \mathrm{dl})$

Abbreviation: $L D L-C$ low-density lipoprotein cholesterol, sdLDL-C small dense LDL-C, IbLDL-C large buoyant LDL-C, TG triglyceride, $T C$ total cholesterol, $H D L-C$ highdensity lipoprotein cholesterol, Apo apolipoprotein, FBG fasting blood glucose, HbAlc hemoglobin A1c, eGFR estimated glomerular filtration rate, $h s$ - $C R P$ high sensitivity C-reaction protein, CVs cardiovascular events 
Table 4 Univariate and multivariate Cox,s proportional hazard analysis predicting for cardiovascular events

\begin{tabular}{|c|c|c|c|}
\hline \multirow[t]{3}{*}{ Variable } & \multirow{3}{*}{$\begin{array}{l}\text { Univariate model } \\
\text { HR } 95 \% \text { Cl }\end{array}$} & \multicolumn{2}{|l|}{ Multivariate model } \\
\hline & & Model 1 & Model 2 \\
\hline & & $\mathrm{HR} 95$ \% Cl & HR $95 \%$ Cl \\
\hline Age & $1.251(1.145-1.590)$ & $1.204(1.032-1.578)$ & $1.214(1.143-1.580)$ \\
\hline Men & $0.801(0.488-1.313)$ & $0.774(0.555-1.086)$ & $0.776(0.553-1.087)$ \\
\hline sdLDL-C & $1.294(1.026-1.633)$ & $1.275(1.016-1.596)$ & $1.280(1.020-1.624)$ \\
\hline sdLDL-C/LDL-C & $2.526(1.653-22.5904)$ & $2.450(1.420-15.630)$ & $2.445(1.402-14.521)$ \\
\hline $\mathrm{LDL}-\mathrm{C}$ & $1.015(0.908-1.131)$ & - & - \\
\hline $\mathrm{HDL}-\mathrm{C}$ & $0.721(0.450-1.130)$ & $0.822(0.475-1.346)$ & - \\
\hline Non-HDL-C & $1.045(0.912-1.118)$ & - & - \\
\hline $\mathrm{LDL}-\mathrm{C} / \mathrm{HDL}-\mathrm{C}$ & $1.167(1.013-1.323)$ & $1.012(0.913-1.124)$ & - \\
\hline Apo A-I & $0.963(0.941-0.992)$ & - & $0.982(0.943-1.142)$ \\
\hline $\mathrm{HbA1c}$ & $1.215(1.133-1.684)$ & $1.204(1.101-1.504)$ & $1.135(1.103-1.497)$ \\
\hline eGFR & $0.965(0.926-0.992)$ & $0.979(0.936-1.002)$ & - \\
\hline hs-CRP & 1.007 (0.912-1.113) & $1.071(0.941-1.085)$ & - \\
\hline
\end{tabular}

Abbreviations are the same as those for Table 3. Model1 was adjusted age, gender, sdLDL-C, sdLDL-C/LDL-C,HDL-C, LDL-C/HDL-C, HbA1C, eGFR, hs-CRP. Model 2 was adjusted age, gender, sdLDL-C, ApoA-I,sdLDL-C/LDL-C,HbA1c. Bold numbers: statistically significant

coronary artery disease and have associated it with the incidence of CVs independently of LDL-C [10, 11]. As discussed above, we also failed to observe any significant impact on CV risk with increased LDL-C. Our multiple regression analysis results also suggested that the common blood lipid and lipoprotein index measures fail to accurately predict CVs, and that increased sdLDL is apparently the most effective atherogenic risk factor in CKD patients [22-25].

It is worth mentioning that sdLDL, which has greater susceptibility to oxidation, is already regarded as a risk marker for CVD [26-32]. There is scientific evidence

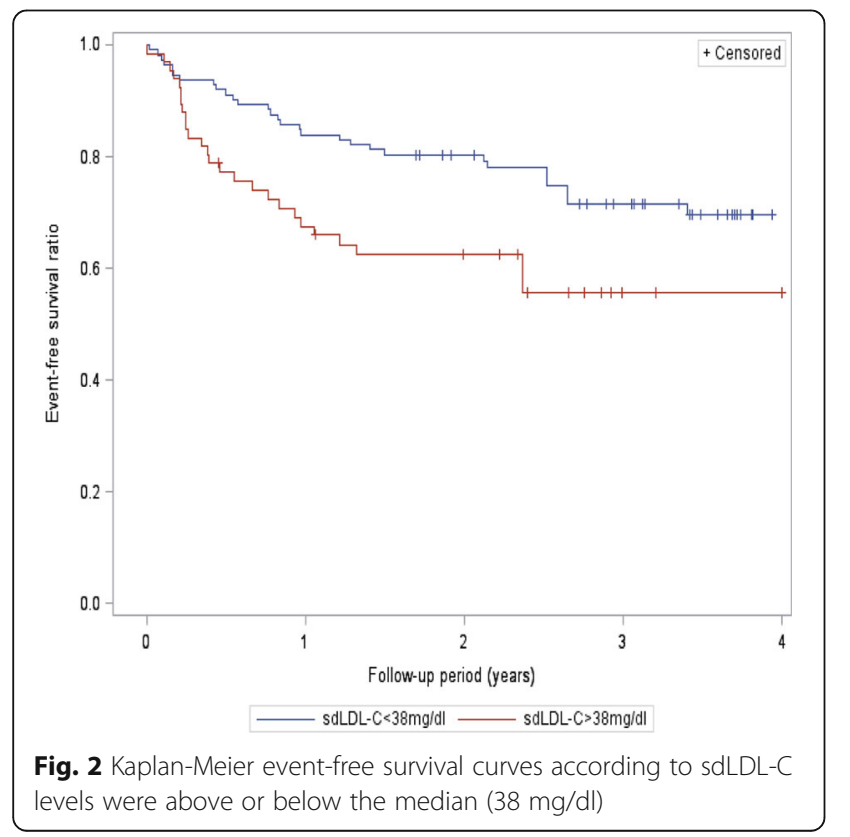

that sdLDL particles are highly atherogenic and can be a biomarker of CVD [30-32]. Traditional methods of detecting sdLDL are generally ineffective, however, as they require laborious and lengthy assay processes [33, 34]. The results of this study support the role of sdLDL-C in regards to CVD risk, and also suggest that routine detection is indeed possible via a new, fully automated, homogenous assay technique.

This study had several potential limitations. First, patients with CVs had more diabetes and hypertension, and these factors were not evaluated. Second, the effects of insulin therapy were not investigated. The small

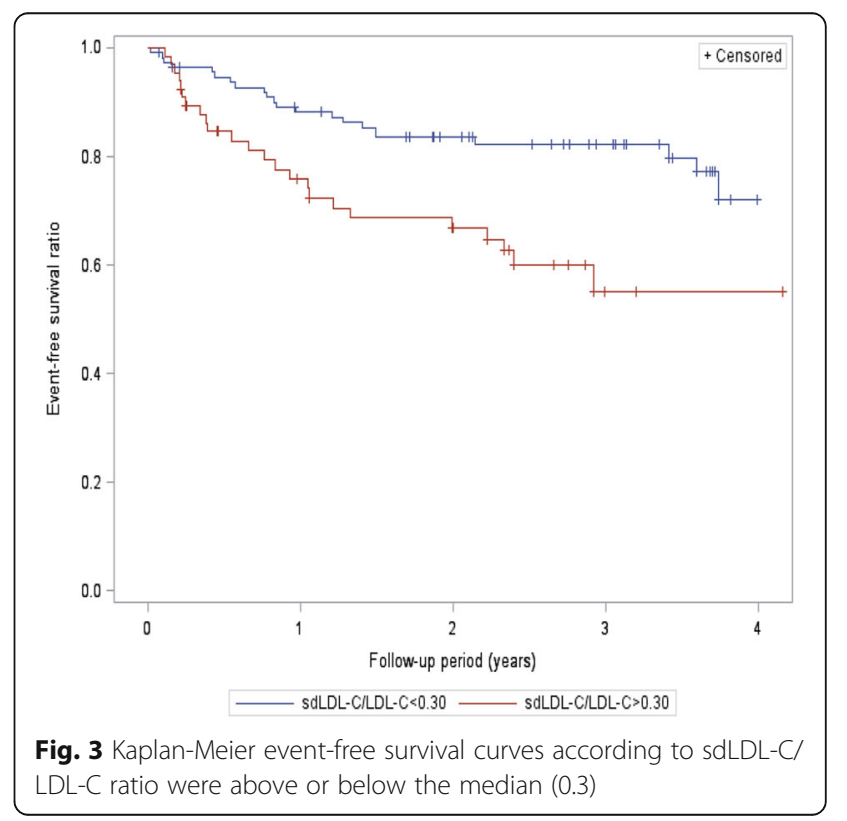


sample size and relatively brief follow-up period were also less than ideal. Finally, the cohort may not be completely representative of the CKD population due to the exclusion of patients treated with lipid-lowering medication. Future studies should focus on resolving these issues, especially with a larger sample size.

\section{Conclusion}

The results of this study indicated that for patients suffering CKD, a significant relationship exists between an elevated sdLDL-C concentration and the risk of cardiovascular disease.

\section{Abbreviations}

Apo: Apolipoprotein; CKD: Chronic kidney disease; CVD: Cardiovascular disease; eGFR: Estimated glomerular filtration rate; FBG: Fasting blood glucose; HbAlc: Hemoglobin A1c; HDL: High-density lipoprotein; HDL-C: HDL cholesterol; HPLC: High performance liquid chromatography; hs-CRP: High sensitivity C-reaction protein; IbLDL: Large buoyant LDL; LDL: Low-density lipoprotein; LDL-C: LDL cholesterol; sdLDL: Small dense LDL; sdLDL-C: Small dense low-density lipoprotein cholesterol; TC: Total cholesterol; TG: Triglyceride

\section{Acknowledgements}

This study was supported by the Renal Unit of Wujiang Affiliated Hospital of Nantong University.

\section{Funding}

Invigorating Health Engineering projects (WWK201417)

\section{Availability of data and materials}

Unfortunately, the initial data cannot be shared as it contains confidential information.

\section{Authors' contributions}

SH and XY planned and supervised the study. LJF, MCF, and ZA contributed to data collection and enrolled patients. LQ performed the flow mediated dilatation test. CX wrote the manuscript. ZYD and SGR reviewed/edited the manuscript. All authors read and approved the final manuscript.

\section{Competing interests}

The authors declare that they have no competing interests.

\section{Consent for publication}

All patients signed an informed consent to the anonymous use of their clincal data for research purposes at submission for treatment.

\section{Ethics approval and consent to participate}

This study was approved by the Committee on Human Research of Wujiang Affiliated Hospital of Nantong University. All patients signed a dedicate informed consent.

\section{Author details}

${ }^{1}$ Department of Clinical Laboratory Medicine, First People's Hospital of Wujiang District, Nantong University, Suzhou, China. ${ }^{2}$ Department of Nephrology, First People's Hospital of Wujiang District, Nantong University, Suzhou, China. ${ }^{3}$ Department of Geriatrics, First People's Hospital of Wujiang District, Nantong University, Suzhou, China.

\section{Received: 28 June 2016 Accepted: 28 September 2016}

\section{Published online: 06 October 2016}

\section{References}

1. Stenvinkel P. Chronic kidney disease: a public health priority and harbinger of premature cardiovascular disease. J Intern Med. 2010;268:456-67.

2. Austin MA, Breslow JL, Hennekens CH, Buring JE, Willett WC, Krauss RM. Lowdensity lipoprotein subclass patterns and risk of myocardial infarction. JAMA. 1988;260:1917-21.
3. Campos H, Genest Jr JJ, Blijlevens E, McNamara JR, Jenner JL, Ordovas JM, Wilson PW, Schaefer EJ. Low density lipoprotein particle size and coronary artery disease. Arterioscler Thromb. 1992;12:187-95.

4. Coresh J, Kwiterovich Jr PO, Smith HH, Bachorik PS. Association of plasma triglyceride concentration and LDL particle diameter, density, and chemical composition with premature coronary artery disease in men and women. J Lipid Res. 1993;34:1687-97.

5. Stalenhoef AF, de Graaf J. Association of fasting and nonfasting serum triglycerides with cardiovascular disease and the role of remnant-like lipoproteins and small dense LDL. Curr Opin Lipidol. 2008;19:355-61.

6. Keith DS, Nichols GA, Gullion CM, Brown JB, Smith DH. Longitudinal followup and outcomes among a population with chronic kidney disease in a large managed care organization. Arch Intern Med. 2004;164:659-63.

7. Carrero JJ, Stenvinkel P. Inflammation in end-stage renal disease-What have we learned in 10 years? Semin Dial. 2010;23:498-509.

8. Stenvinkel P, Carrero JJ, Axelsson J, Lindholm B, Heimbürger O, Massy Z. Emerging biomarkers for evaluating cardiovascular risk in the chronic kidney disease patient: how do new pieces fit into the uremic puzzle? Clin J Am Soc Nephrol. 2008;3:505-21.

9. Levin NW, Handelman GJ, Coresh J, Port FK, Kaysen GA. Reverse epidemiology: a confusing, confounding, and inaccurate term. Semin Dial. 2007;20:586-92.

10. Ai M, Otokozawa S, Asztalos BF, Ito Y, Nakajima K, White CC, et al. Small dense LDL cholesterol and coronary heart disease: results from the Framingham offspring study. Clin Chem. 2010;56:967-76.

11. Arai H, Kokubo Y, Watanabe M, Sawamura T, Ito Y, Minagawa A, et al. Small dense low-density lipoproteins cholesterol can predict incident cardiovascular disease in an urban Japanese cohort: the Suita study. J Atheroscler Thromb. 2013:20:195-203.

12. National Kidney Foundation. K/DOQI clinical practice guidelines for chronic kidney disease: evaluation, classification and stratification. Am J Kidney Dis. 2002;39:S1-266.

13. Chobanian AV, Bakris GL, Black HR, Cushman WC, Green LA, Izzo Jr JL, et al. The seventh report of the joint national committee on prevention, detection, evaluation, and treatment of high blood pressure: the jnc 7 report. JAMA. 2003;289:2560-72.

14. American Diabetes Association. Executive summary: standards of medical care in diabetes-2011. Diabetes Care. 2011;34(Suppl 1):S4-10.

15. Expert Panel on Detection, Evaluation, and Treatment of High Blood Cholesterol in Adults. Executive Summary of The Third Report of The National Cholesterol Education Program (NCEP) Expert Panel on Detection, Evaluation, And Treatment of High Blood Cholesterol In Adults (Adult Treatment Panel III). JAMA. 2001;285:2486-97.

16. Levey AS, Bosch JP, Lewis JB, Greene T, Rogers N, Roth D. A more accurate method to estimate glomerular filtration rate from serum creatinine: a new prediction equation. Modification of Diet in Renal Disease Study Group. Ann Intern Med. 1999;130:461-70.

17. Seino Y, Nanjo K, Tajima N, Kadowaki T, Kashiwagi A, Araki E. The Committee of Japan Diabetes Society on the diagnostic criteria of diabetes mellitus: report of the Committee on the classification and diagnostic criteria of diabetes mellitus. J Diabetes Invest. 2010;1:212-28.

18. Shen H, Zhou J, Shen G, Yang H, Lu Z, Wang H. Correlation between serum levels of small, dense low-density lipoprotein cholesterol and carotid stenosis in cerebral infarction patients > 65 years of age. Ann Vasc Surg. 2014;28:375-80.

19. Rubin C, Nolin TD, Himmelfarb J. Are biomarkers useful for assessing cardiovascular risk in patients with chronic kidney disease? Curr Opin Nephrol. 2007;16:506-11.

20. Kanbay M, Siriopol D, Saglam M, Gulcan Kurt Y, Gok M, Cetinkaya H, et al. Serum sclerostin and adverse outcomes in non-dialyzed chronic kidneydisease patients. J Clin Endocrinol Metab. 2014;99 suppl 10:E1854-61.

21. Saab G, Bomback AS, McFarlane SI, Li S, Chen SC, McCullough PA, et al. The association of parathyroid hormone with ESRD and pre-ESRD mortality in the Kidney Early Evaluation Program. J Clin Endocrinol Metab. 2012;97:4414-21.

22. Tonelli M, Muntner P, Lloyd A, Manns B, Klarenbach S, Pannu N, et al. Association between LDL-C and risk of myocardial infarction in CKD. Alberta Kidney Disease Network. J Am Soc Nephrol. 2013;24:979-86.

23. Holzmann MJ, Jungner I, Walldius G, Ivert T, Nordqvist T, Ostergren J, et al. Dyslipidemia is a strong predictor of myocardial infarction in subjects with chronic kidney disease. Ann Med. 2012;44:262-70.

24. Quaschning T, Krane V, Metzger T, Wanner C. Abnormalities in uremic lipoprotein metabolism and its impact on cardiovascular disease. Am J Kidney Dis. 2001;38:S14-9. 
25. Rizzo M, Berneis K. Low-density lipoprotein size and cardiovascular risk assessment. QJM. 2006;99:1-14.

26. Varbo A, Benn M, Tybjaerg-Hansen A, Jorgensen AB, Frikke-Schmidt R, Nordestgaard BG. Remnant cholesterol as a causal risk factor for ischemic heart disease. J Am Coll Cardiol. 2013;61:427-36.

27. Hoogeveen RC, Gaubatz JW, Sun W, Dodge RC, Crosby JR, Jiang J, et al. Small dense low-density lipoprotein-cholesterol concentrations predict risk for coronary heart disease: the atherosclerosis risk in communities (ARIC) study. Arterioscler Thromb Vasc Biol. 2014;34:1069-77.

28. Décary S, Dumon G, Lamarche B, Hoque JC, Tremblay AJ, Bergeron J, et al. Assessment of the validity of the frequently used lipid indices for predicting LDL peak particle diameter in a large cohort of 1955 normal and dyslipidemic subjects. Clin Brioche. 2010;43:401-6.

29. Mikhailidis DP, Elisaf M, Rizzo M, Berneis K, Griffin B, Zambon A, et al. "European panel on low density lipoprotein (LDL) subclasses": a statement on the pathophysiology, atherogenicity and clinical significance of LDL subclasses: executive summary. Curr Vasc Pharmacol. 2011;9:531-2.

30. St-Pierre AC, Cantin B, Dagenais GR, Mauriège P, Bernard PM, Després JP, et al. Low-density lipoprotein subfractions and the long-term risk of ischemic heart disease in men: 13-year follow-up data from the Québec Cardiovascular Study. Arterioscler Thromb Vasc Biol. 2005;25:553-9.

31. Tsai MY, Steffen BT, Guan W, McClelland RL, Warnick R, McConnell J. New automated assay of small dense low-density lipoprotein cholesterol identifies risk ofcoronary heart disease: the multi-ethnic study of atherosclerosis. Arterioscler Thromb Vasc Biol. 2014;34(1):196-201.

32. Koba S, Yokota Y, Hirano T, Ito Y, Ban Y, Tsunoda F, et al. Small LDLcholesterol is superior to LDL-cholesterol for determining severe coronary atherosclerosis. J Atheroscler Thromb. 2008;15:250-60.

33. Swinkels DW, Hak-Lemmers HL, Demacker PN. Single spin density gradient ultracentrifugation method for the detection and isolation of light and heavy low density lipoprotein subfractions. J Lipid Res. 1987;28:1233-9.

34. Nichols AV, Krauss RM, Musliner TA. Nondenaturing polyacrylamide gradient gel electrophoresis. Methods Enzymol. 1986;128:417-31.

\section{Submit your next manuscript to BioMed Central and we will help you at every step:}

- We accept pre-submission inquiries

- Our selector tool helps you to find the most relevant journal

- We provide round the clock customer support

- Convenient online submission

- Thorough peer review

- Inclusion in PubMed and all major indexing services

- Maximum visibility for your research

Submit your manuscript at www.biomedcentral.com/submit 